\title{
A Site-Specific Response Analysis: A Case Study in Hanoi, Vietnam
}

\author{
Van-Quang Nguyen ${ }^{1,2}{ }^{(D)}$, Muhammad Aaqib ${ }^{1}$, Duy-Duan Nguyen ${ }^{2,3}{ }^{\mathbb{D}}$, Nguyen-Vu Luat ${ }^{4,5}$ \\ and Duhee Park $1, *$ (D) \\ 1 Department of Civil and Environmental Engineering, Hanyang University, Seoul 04763, Korea; \\ nguyenvanquang240484@gmail.com (V.-Q.N.); aqi443@hotmail.com (M.A.) \\ 2 Department of Civil Engineering, Vinh University, Vinh 461010, Vietnam; duan468@gmail.com \\ Department of Civil Engineering, Konkuk University, Seoul 05029, Korea \\ Department of Architectural Engineering, Sejong University, Seoul 05006, Korea; luatnv@tlu.edu.vn \\ Department of Civil Engineering, Thuyloi University, 175 Tay Son, Hanoi 115000, Vietnam \\ * Correspondence: dpark@hanyang.ac.kr; Tel.: +82-2-2220-0322
}

Received: 17 April 2020; Accepted: 4 June 2020; Published: 8 June 2020

\begin{abstract}
A series of one-dimensional (1-D) site response analyses were performed using the nonlinear (NL) and equivalent linear (EQL) approaches to assess the applicability of the Vietnamese earthquake-resistance design code TCVN 9386: 2012. Six soil profiles were selected from three districts in Hanoi (Vietnam). A number of ground motions compatible with the rock design spectrum were used as input for carrying out analyses. The results highlight that the calculated response is higher than the design spectrum for site class $C$ and lower for site class $D$. The normalized response spectra of the EQL approach results are higher than those of the NL approach. Moreover, the peak ground accelerations at the surface from EQL analyses are greater than those of the NL method because the latter generates a higher amount of nonlinearity. The results from the NL approach also illustrate that the deamplification phenomenon occurs in the soft soils of the Hanoi region (e.g., soil profile P3 and P5 of site class D). Additionally, the shear strains calculated from the NL method are closely matched with those from the EQL method, the difference between them increasing with a decrease in soil stiffness.
\end{abstract}

Keywords: earthquake; seismic; design response spectrum; one-dimensional site response analysis; nonlinear approach; equivalent linear approach

\section{Introduction}

The study of earthquake ground motions and associated earthquake risks plays an important role in the sustainable development of earthquake-prone countries. Site response analyses are usually performed to analyze ground amplification and to develop the design response spectra [1].

The northern part of Vietnam is located in the plate boundary between the South China plate and the Indochina plate. The plate boundary is the Red River fault zone that strikes in the NW-SE direction and extends over a length of $1000 \mathrm{~km}$ between the Gulf of Tonkin and Tibet [2]. It caused large scale displacement and major tectonic features in Vietnam, such as rifting and folding. Hanoi is located to the North and the capital of Vietnam lies in the center of the triangular basin of the Red River. The center of the city is placed on the south bank of the river. Most of the deltaic land lies on both sides of the Red River and its tributaries. Hanoi is also affected by many adjacent zones such as the Lai Chau-Dien Bien (LC-DB), Son La, Ma River, Lo River, and Chay River faults (Figure 1) [3]. 


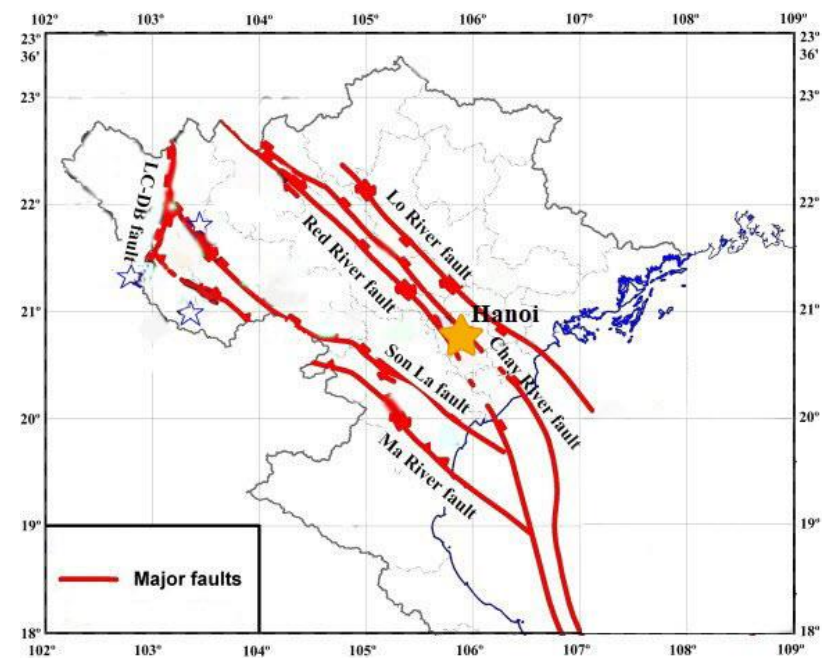

Figure 1. Map of major faults in the north of Vietnam [3].

A total of 1645 earthquakes with a local magnitude $\left(\mathrm{M}_{\mathrm{L}}\right)$ of 3.0 and higher were recorded in Vietnam from 114 to 2003 [4]. There were three earthquakes recorded at Hanoi in 1276, 1278, and 1285 with $\mathrm{M}_{\mathrm{L}}=5.5-6.0$. In 1983, several moderate earthquakes happened in the northern provinces of Vietnam. However, even with a distance of approximately $300 \mathrm{~km}$ from these epicenters, the people of Hanoi experienced a strong vibration and a number of buildings were damaged. It revealed that amplification of seismic ground motion through soft soil caused a high amplification. Recently, earthquakes occurred in the neighboring provinces of Hanoi such as Dien Bien in 2001, Ha Giang in 2005, Ninh Binh in 2005, and Hoa Binh in 2010 with a $\mathrm{M}_{\mathrm{L}}$ of 5.3, 4.7, 3.1, and 4.0, respectively.

Site-specific ground response analysis is a usual practice to predict the local site condition effects. Shylamoni et al. [5] performed the site-specific one-dimensional (1-D) equivalent linear (EQL) site response analysis for the nuclear power plants in Japan. Grasso and Maugeri [6] carried out the seismic response analysis on the Italian site conditions to develop a seismic microzoning map for Catania City. Naik and Choudhury [7] conducted the 1-D EQL site response analysis for Goa City in India using the data of the Bhuj earthquake 2001. Recently, Aaqib et al. [8] performed 1-D nonlinear site response analyses for the Korean sites to investigate the effect of strength correction on the seismic site coefficients. Mahmood et al. [9] implemented the 1-D EQL site response analysis for sites in Islamabad, Pakistan.

Due to the recent earthquakes as well as the urban infrastructure development, the impact of the earthquake in Hanoi has also been considered and studied by performing site-specific seismic response analyses [10-13]. Nhung et al. [10] and Alexandr and Chi [11] assessed the hazard and possibility of liquefaction of soil layers caused by earthquakes in the urban area of the city. Wen et al. [13] concluded that the soil deposit in the Hanoi region may increase earthquake damage because of the amplification of ground motion after performing site response analysis from the microtremor survey. The current seismic design code of Vietnam, TCVN 9386:2012 [14], was constructed based on Eurocode 8 (EC-8) [15] with consideration of the Vietnamese seismic map. The above-mentioned studies revealed that there is limited literature available on the site-specific response analysis in Vietnam. The relative difference between the design spectra based on the site-specific amplification factors and the code-based spectra has not been investigated yet. Moreover, all the aforesaid studies did not consider a range of input motions to account for the variability in frequency contents of ground motions.

The purpose of this study is to perform site-specific nonlinear (NL) and EQL response analyses based on the profiles from different locations of Central Hanoi City (Vietnam), using a range of input ground motions. The obtained spectra shapes are compared with those of the Vietnamese seismic design code, TCVN 9386:2012, and differences between NL and EQL methods are thoroughly discussed. 


\section{An Insight of the Vietnamese Seismic Design Code TCVN 9386: 2012}

The TCVN 9386: 2012 was developed based on EC-8. However, there were some significant changes [4] to conform with the local Vietnamese conditions. Firstly, the seismic map has been developed from the data obtained from Vietnam Institute of Geophysics (VIG) [16] as shown in Figure 2. Secondly, the importance factors and importance classes in TCVN 9386: 2012 are slightly different from those of EC-8. In TCVN 9386: 2012, there were five importance classes with importance factors ranged from 0.75 to the value corresponding to the possible maximum acceleration. Note that there is no required earthquake resistance for the final importance class (i.e., class IV) in the Vietnamese design code, whereas the EC-8 is classified into four importance classes with importance factors ranged from 0.8 to 1.4. The importance classes and importance factors specified by EC-8 and TCVN 9386: 2012 are listed in Tables 1 and 2, respectively. Thirdly, as the strongest earthquake regions have a magnitude greater than 5.5 on the local magnitude scale and lack data to establish the spectral curves, the TCVN 9386: 2012 used only the type 1 elastic response spectra in two types of EC-8 as the design response spectrum for all regions in Vietnam. Figure 3a shows the detailed type 1 elastic response spectra of EC-8 or the design response spectrum in TCVN 9386: 2012.

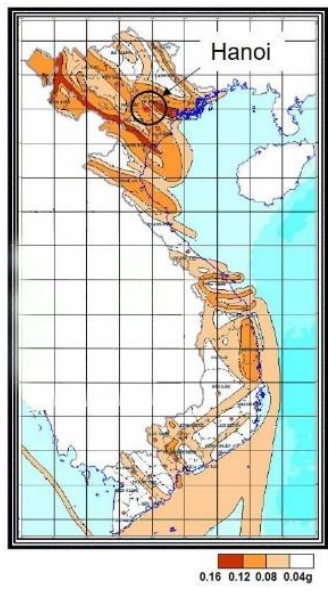

(a)

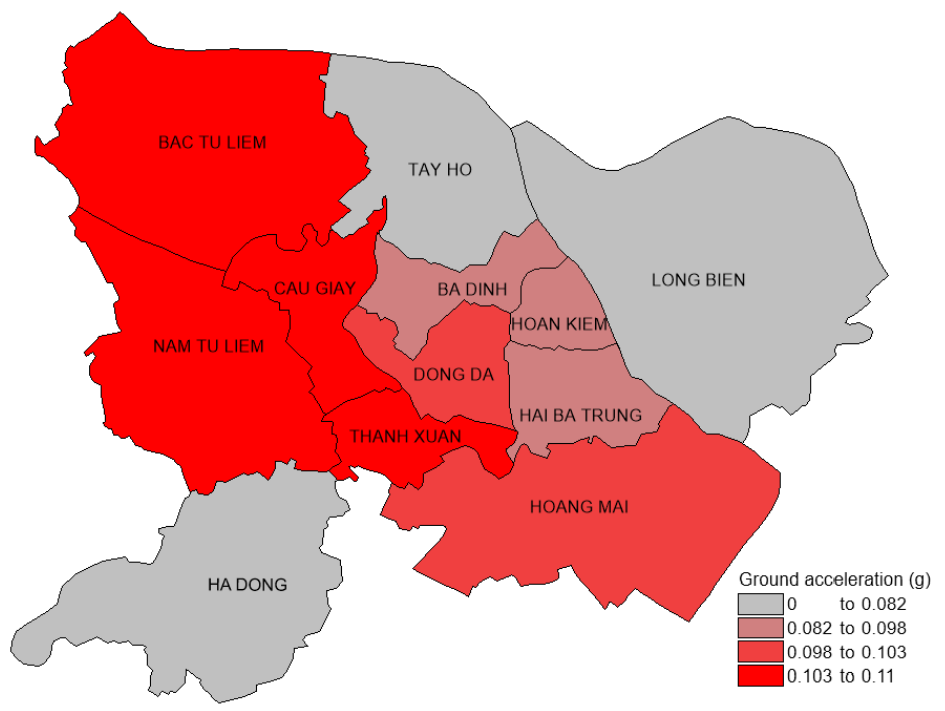

(b)

Figure 2. Ground acceleration map for (a) Vietnam [4] and (b) Hanoi.

Table 1. Importance class and recommended importance factors values in Eurocode 8 (EC-8) [15].

\begin{tabular}{|c|c|c|}
\hline Importance Class & Buildings & $\begin{array}{l}\text { Recommended Importance } \\
\text { Factor, } \gamma_{\mathrm{I}}\end{array}$ \\
\hline I & $\begin{array}{l}\text { Building of minor importance for public safety, e.g., } \\
\text { agricultural building, etc. }\end{array}$ & 0.8 \\
\hline II & $\begin{array}{l}\text { Ordinary building, not belonging in the other categories } \\
\text { Building whose seismic resistance is of importance in }\end{array}$ & 1.0 \\
\hline III & $\begin{array}{l}\text { view of the consequences associated with a collapse, e.g., } \\
\text { schools, assembly halls, cultural institutions, etc. }\end{array}$ & 1.2 \\
\hline IV & $\begin{array}{c}\text { Building whose integrity during earthquakes is of vital } \\
\text { importance of civil protection, e.g., hospitals, fire } \\
\text { stations, power plants, etc. }\end{array}$ & 1.4 \\
\hline
\end{tabular}


Table 2. Importance class and recommended importance factors values in TCVN 9386: 2012 [14].

\begin{tabular}{|c|c|c|}
\hline Importance Class & Buildings & $\begin{array}{l}\text { Recommended Importance } \\
\text { Factor, } \gamma_{\mathrm{I}}\end{array}$ \\
\hline Special & $\begin{array}{c}\text { The building has special importance, not allowing any } \\
\text { damage by the earthquake. }\end{array}$ & $\begin{array}{l}\text { Designed with maximum } \\
\text { possible acceleration }\end{array}$ \\
\hline I & $\begin{array}{c}\text { The building has vital importance for the protection of } \\
\text { the community, its function must not be interrupted } \\
\text { during the earthquake. }\end{array}$ & 1 \\
\hline II & $\begin{array}{l}\text { The building has an importance in preventing } \\
\text { earthquake consequences, if collapsed causing great loss } \\
\text { of life and property. }\end{array}$ & 1.0 \\
\hline III & $\begin{array}{l}\text { The building does not belong to importance classes: } \\
\text { special, I, II, and IV. }\end{array}$ & \\
\hline IV & $\begin{array}{l}\text { The building has minor importance for the safety of } \\
\text { human life. }\end{array}$ & 0.75 \\
\hline
\end{tabular}

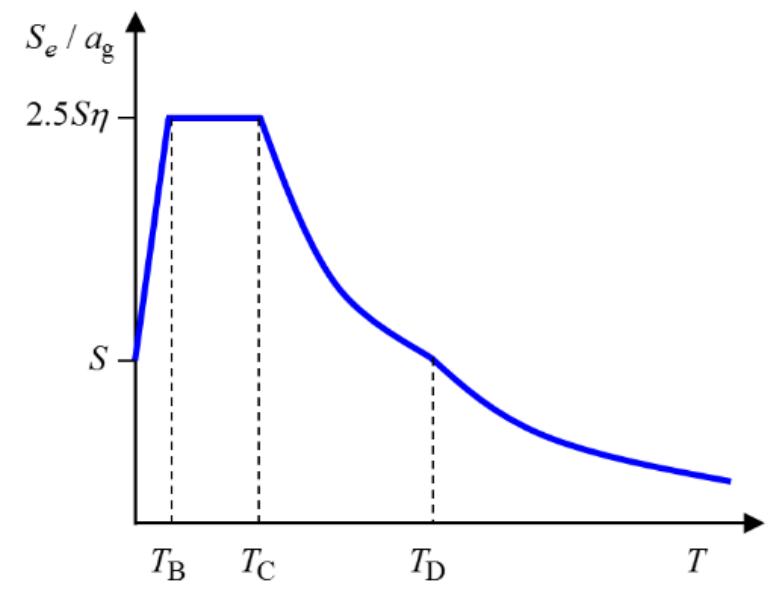

(a)

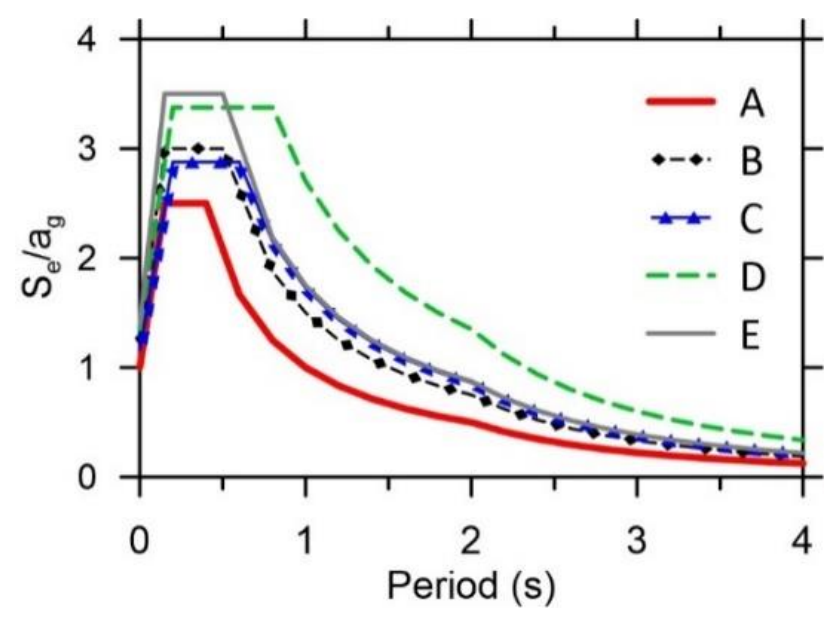

(b)

Figure 3. Elastic response spectra (5\% damping) [4]: (a) general type and (b) for ground types A to E.

The horizontal elastic response spectrum $S_{e}(T)$ is determined by the following expressions:

$$
\begin{gathered}
0 \leq T \leq T_{\mathrm{B}}: S_{\mathrm{e}}(T)=a_{\mathrm{g}} \cdot S \cdot\left[1+\frac{T}{T_{\mathrm{B}}} \cdot(\eta \cdot 2.5-1)\right] \\
T_{\mathrm{B}} \leq T \leq T_{\mathrm{C}}: S_{\mathrm{e}}(T)=a_{\mathrm{g}} \cdot S \cdot \eta \cdot 2.5
\end{gathered}
$$




$$
\begin{gathered}
T_{\mathrm{C}} \leq T \leq T_{\mathrm{D}}: S_{\mathrm{e}}(T)=a_{\mathrm{g}} \cdot S \cdot \eta \cdot 2.5 \cdot\left[\frac{T_{\mathrm{C}}}{T}\right] \\
T_{\mathrm{B}} \leq T \leq T_{\mathrm{C}}: S_{\mathrm{e}}(T)=a_{\mathrm{g}} \cdot S \cdot \eta \cdot 2.5
\end{gathered}
$$

where:

$S_{e}(T)$ : is the elastic response spectrum.

$T$ : is the vibration period of a linear single-degree-of-freedom system.

$a_{\mathrm{g}}$ : is the design ground acceleration on type A ground $\left(a_{\mathrm{g}}=\gamma_{\mathrm{I}} \cdot a_{\mathrm{gR}}\right)$.

$T_{\mathrm{B}}$ : is the lower limit of the period of the constant spectral acceleration branch.

$T_{C}$ : is the upper limit of the period of the constant spectral acceleration branch.

$T_{\mathrm{D}}$ : is the value defining the beginning of the constant displacement response range of the spectrum. $S$ : is the soil factor.

$\eta$ : is the damping correction factor with a reference value of $\eta=1$ for viscous damping $\xi=5 \%$

$$
\begin{gathered}
\eta=10 /(5+\xi) \geq 0.55 \text { in TCVN 9386 : } 2012 \\
\eta=\sqrt{10 /(5+\xi)} \geq 0.55 \text { in EC }-8
\end{gathered}
$$

For the five soil types, A, B, C, D, and E, the values of parameters $S, T_{B}, T_{C}$, and $T_{D}$ are given in Table 3 , and normalized shapes by $a_{\mathrm{g}}$ for $5 \%$ damping are shown in Figure $3 \mathrm{~b}$.

Table 3. Values of parameters describing elastic response spectra $[14,15]$.

\begin{tabular}{ccccc}
\hline Ground Type & $\boldsymbol{S}$ & $\boldsymbol{T}_{\mathbf{B}}(\mathbf{s})$ & $\boldsymbol{T}_{\mathbf{C}}(\mathbf{s})$ & $\boldsymbol{T}_{\mathbf{D}}(\mathbf{s})$ \\
\hline $\mathrm{A}$ & 1.0 & 0.15 & 0.4 & 2.0 \\
$\mathrm{~B}$ & 1.2 & 0.15 & 0.5 & 2.0 \\
$\mathrm{C}$ & 1.15 & 0.2 & 0.8 & 2.0 \\
$\mathrm{D}$ & 1.35 & 0.2 & 0.8 & 2.0 \\
$\mathrm{E}$ & 1.4 & 0.15 & 0.5 & 2.0 \\
\hline
\end{tabular}

\section{Site Response Analysis Methodology}

DEEPSOIL v7.0 [17] was used to perform equivalent linear and nonlinear 1-D site response analyses. The most widely used pressure-dependent hyperbolic, the Modified Kodner-Zelasko (MKZ) model [18], implemented in DEEPSOIL, was used. The dynamic curves proposed by Darendeli [19] were adopted. The variables required to generate the nonlinear curves for each layer are the coefficient of lateral earth pressure $\left(K_{0}\right)$, plasticity index $(\mathrm{PI})$, number and frequency of cycles $(N)$, loading frequency $(f)$, and over consolidation ratio (OCR). Because of the unavailability of site-specific index properties, PI for the sand and clay was assumed as $0 \%$ and $15 \%$ [20-25], respectively, whereas OCR was taken as $1 . N$ and $f$ were set to 10 and 1, respectively, as recommended by Darendeli [19], Ding et al. [22], and Harmon et al. [23]. $K_{0}$ was calculated as 0.5 using the Jacky [26] equation based on the representative friction angle of 30 degrees, as specified in the laboratory investigation report. Small strain damping $\left(D_{\min }\right)$ was also modeled using the functions of Darendeli [19], which predicts generally larger damping values near the ground surface, whereas it keeps on decreasing along with the depth. Figure 4 shows the site response analysis flowchart in this study. A detailed discussion about soil profiles, input ground motions is presented in sections below. 


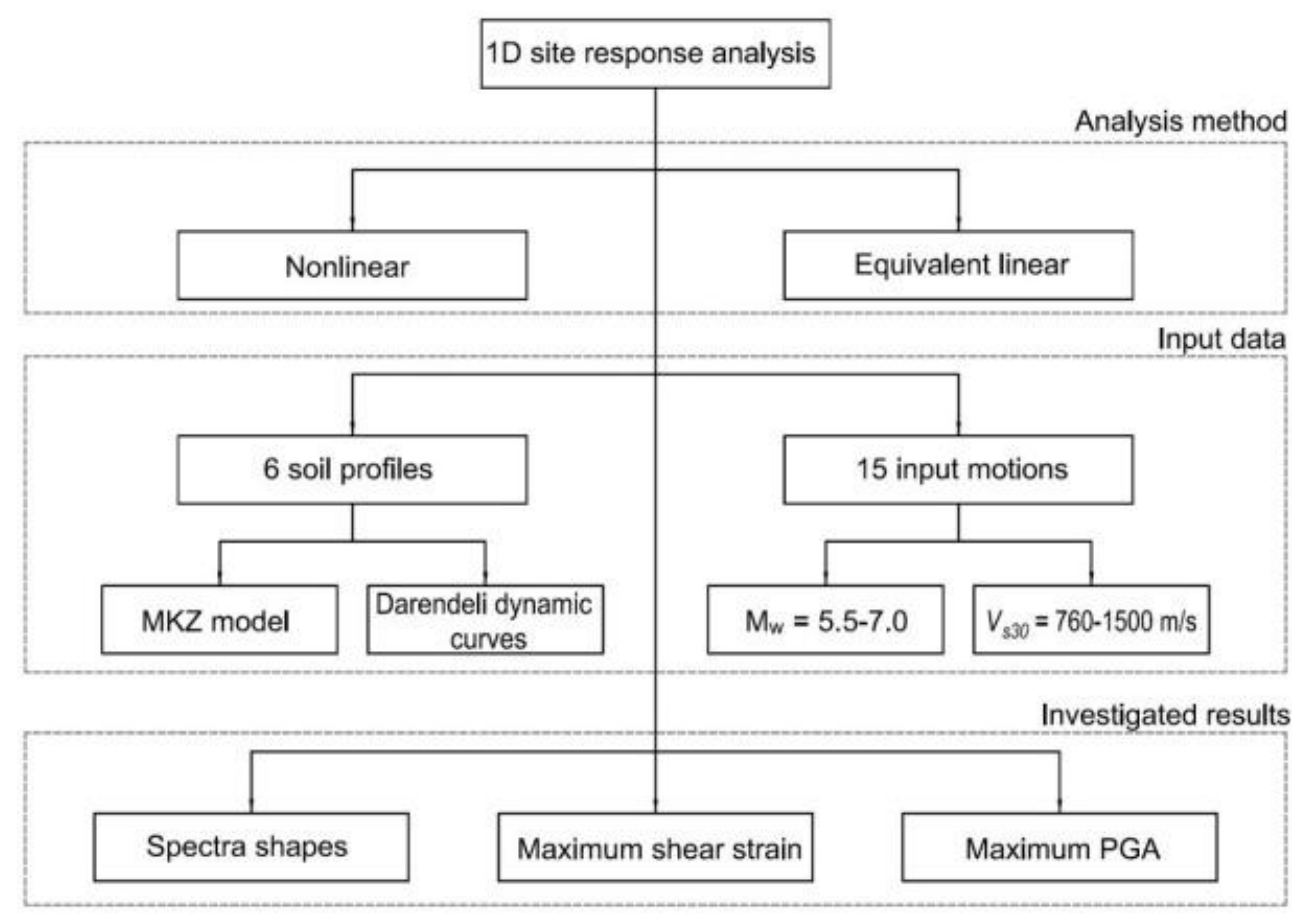

Figure 4. Site response analysis procedure in this study.

\subsection{Soil Profiles}

A total of three districts in Hanoi were selected for the analyses. Two soil profiles were selected from Cau Giay District (District 1), one from Hoang Mai District (District 2), and three soil profiles were selected from Hai Ba Trung District (District 3). The typical soil stratigraphy includes fill, sand, clay, and gravel. Due to the lack of shear wave velocity $\left(V_{S}\right)$ profile measurements, the in situ standard penetration test blow count (SPT-N) measurements were used to evaluate the $V_{S}$ profiles. The correlation between SPT-N and $V_{S}$ proposed by Marto et al. [27] was used to determine the $V_{S}$ profiles. This correlation was also employed by Trung et al. [28] for Vietnamese soil conditions, expressed as:

$$
V s=77.13 N^{0.377}
$$

The depth to bedrock of the profiles range from $33 \mathrm{~m}$ to $75 \mathrm{~m}$. Natural periods of the sites range from 0.64 to $1.39 \mathrm{~s}$. The time-average shear wave velocity to $30 \mathrm{~m}$ depth $\left(V_{\mathrm{S} 30}\right)$ of the sites range from $160 \mathrm{~m} / \mathrm{s}$ to $202 \mathrm{~m} / \mathrm{s}$. Sites are classified as types C and D according to the Vietnamese design code. The bedrock is considered at the point where the $V_{\mathrm{S}}$ reached to $800 \mathrm{~m} / \mathrm{s}$, according to the bedrock definition in TCVN 9386: 2012. The detail of soil profiles is shown in Table 4 and Figure 5.

Table 4. Soil profile properties.

\begin{tabular}{cccc}
\hline Soil Profile & $\begin{array}{c}\text { Soil Class (According to } \\
\text { EC-8 and TCVN 9386: 2012) }\end{array}$ & Location & Notation \\
& C & Cau Giay District & 1-C \\
P1 & (District 1) & 1-C \\
P2 & C & Cau Giay District & 2-D \\
P3 & D & Hoang Mai District (District 2) & 3-C \\
P4 & C & Hai Ba Trung District (District 3) & 3-D \\
P5 & D & Hai Ba Trung District & 3-D \\
P6 & D & Hai Ba Trung District & \\
\hline
\end{tabular}




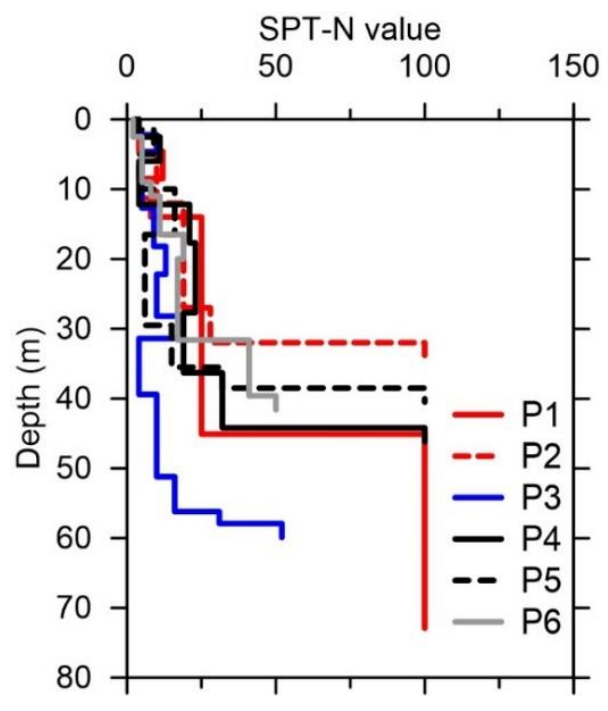

(a)

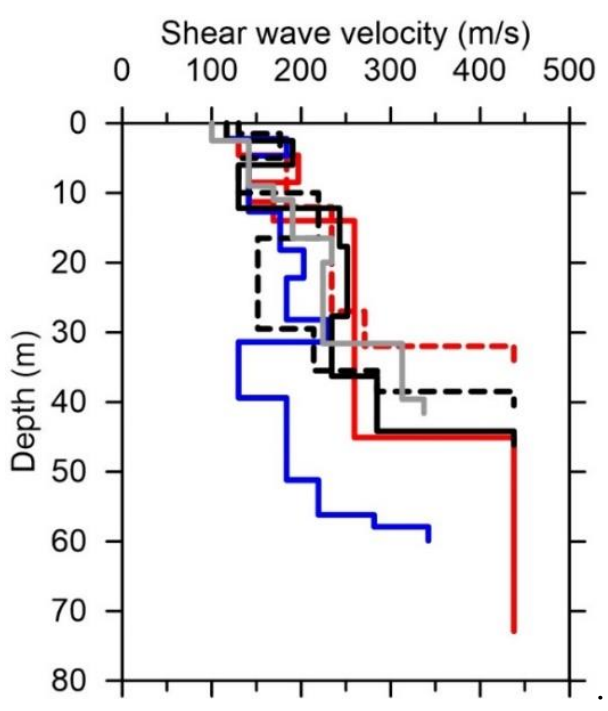

(b)

Figure 5. Selected soil profiles: (a) SPT-N value, (b) shear wave velocity.

\subsection{Input Ground Motions}

To ensure an appropriate representation of ground motion intensities for the districts in Hanoi, earthquake motions representing the seismicity of the region were selected. Due to the lack of earthquake records available in Hanoi, ground motions recorded in other regions with a range of magnitude similar to the ancient earthquakes in Vietnam were selected. The ground motions recorded from earthquakes having a variety of rupture mechanisms were selected to account for the effect of the fault mechanism. The recorded ground motions were selected from the NGA-west 2 database (https://ngawest2.berkeley.edu/). The ground motions with the following features were selected:

- $\quad$ A range of moment magnitudes $\left(\mathrm{M}_{\mathrm{w}}\right)$ 5.5-7.0.

- $\quad$ Rupture distance $\left(\mathrm{R}_{\text {rup }}\right)$ 0.92-85.17 km.

- $\mathrm{V}_{S 30}$ of $760-1500 \mathrm{~m} / \mathrm{s}$.

A total of 15 motions with peak ground acceleration (PGA) ranging from $0.04 \mathrm{~g}$ to $0.25 \mathrm{~g}$ were selected from six earthquake events, as shown in Table 5 . The ground motions were scaled to the 
representative shaking intensity levels of each analyzed district, in which PGA levels at Cau Giay, Hoang Mai, and Hai Ba Trung Districts are scaled to 0.1032 g, 0.1001 g, and 0.0959 g, respectively. Furthermore, the mean response spectrum of the input ground motions matched closely to the target spectrum of site class A of the Vietnamese design code [14], as shown in Figure 6.

Table 5. Selected earthquake events.

\begin{tabular}{|c|c|c|c|c|c|c|c|}
\hline No & Earthquake Name & Year & Station & $\begin{array}{l}\text { Mag. } \\
\left(\mathbf{M}_{W}\right)\end{array}$ & Mechanism & $\begin{array}{c}R_{\text {rup }} \\
(\mathrm{Km})\end{array}$ & $\begin{array}{l}V_{S 30} \\
(\mathrm{~m} / \mathrm{s})\end{array}$ \\
\hline 1 & San Fernando & 1971 & $\begin{array}{l}\text { Pasadena-Old } \\
\text { Seismo Lab }\end{array}$ & 6.61 & Reverse & 21.5 & 969.07 \\
\hline 2 & Whittier Narrows-01 & 1987 & $\begin{array}{c}\text { Pasadena-CIT } \\
\text { Kresge Lab }\end{array}$ & 5.99 & Reverse & 18.12 & 969.07 \\
\hline 3 & Loma Prieta & 1989 & $\begin{array}{l}\text { Piedmont Jr High } \\
\text { School Grounds }\end{array}$ & 6.93 & $\begin{array}{l}\text { Reverse } \\
\text { Oblique }\end{array}$ & 73 & 895.36 \\
\hline 4 & Loma Prieta & 1989 & Point Bonita & 6.93 & $\begin{array}{l}\text { Reverse } \\
\text { Oblique }\end{array}$ & 83.45 & 1315.92 \\
\hline 5 & Loma Prieta & 1989 & SF-Pacific Heights & 6.93 & $\begin{array}{l}\text { Reverse } \\
\text { Oblique }\end{array}$ & 75.96 & 1249.86 \\
\hline 6 & Loma Prieta & 1989 & $\begin{array}{c}\text { So. San } \\
\text { Francisco_Sierra Pt. }\end{array}$ & 6.93 & $\begin{array}{l}\text { Reverse } \\
\text { Oblique }\end{array}$ & 63.15 & 1020.62 \\
\hline 7 & Northridge-01 & 1994 & LA-Wonderland Ave & 6.99 & Reverse & 20.29 & 1222.52 \\
\hline 8 & Northridge-01 & 1994 & Vasquez Rocks Park & 6.99 & Reverse & 23.64 & 996.43 \\
\hline 9 & Chi-Chi_Taiwan-05 & 1999 & TTN042 & 6.20 & Reverse & 85.17 & 845.34 \\
\hline 10 & Umbria-03_Italy & 1984 & Gubbio & 5.60 & Normal & 15.72 & 922 \\
\hline 11 & Kobe_Japan & 1995 & Kobe University & 6.90 & Strike slip & 0.92 & 1043 \\
\hline 12 & Chi-Chi_Taiwan-05 & 1999 & HWA002 & 6.20 & Reverse & 45.03 & 789.18 \\
\hline
\end{tabular}

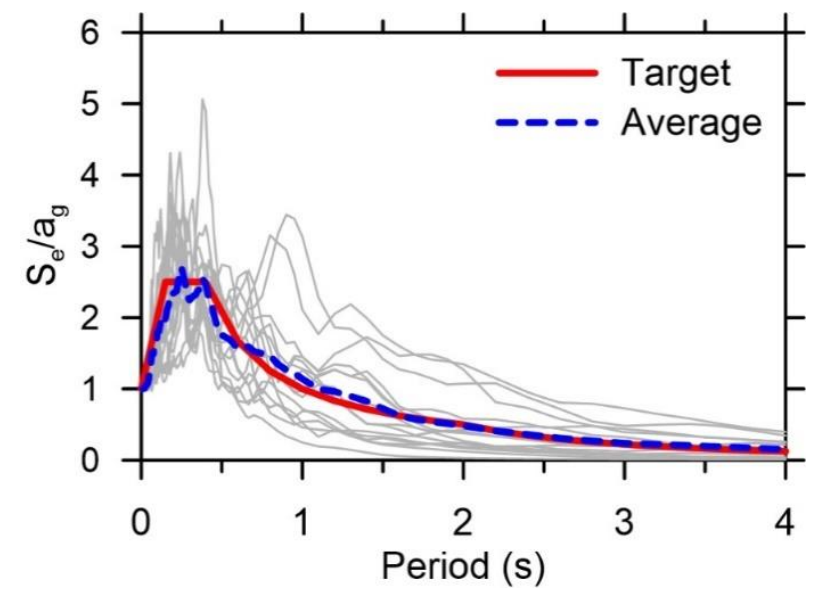

Figure 6. Comparison of selected input ground motions with the target spectrum.

\section{Spectral Shapes}

The soil nonlinearity can be characterized either through the equivalent linear or the fully nonlinear approach. In this section, the normalized spectral shapes from both the NL and EQL approaches are compared with the normalized design spectrum from TCVN 9386: 2012 to evaluate the applicability of the design code.

Figures 7 and 8 compare the spectral shapes from the NL and EQL analyses with the design spectrum for the profiles of both site classes $C$ and D. Districts 1 and 3 consist of site class $C$ profiles. The mean normalized spectrum calculated in this study is higher than the normalized design spectrum for the period range from 0.6 to $2 \mathrm{~s}$ in the case of both the NL and EQL approaches. District 2 and District 3 consist of site class D profiles. The normalized spectral shape is lower than the design spectrum across the whole period range in the case of the NL method, whereas it matches the design spectrum well in the case of the EQL method. The underestimation of calculated spectral shape in the case of the NL approach can be attributed to the high levels of nonlinearity induced because of the 
softness of site class D profiles, which could lead to a certain amount of deamplification. It should be noted that most building periods are greater than $0.3 \mathrm{~s}$ [29].
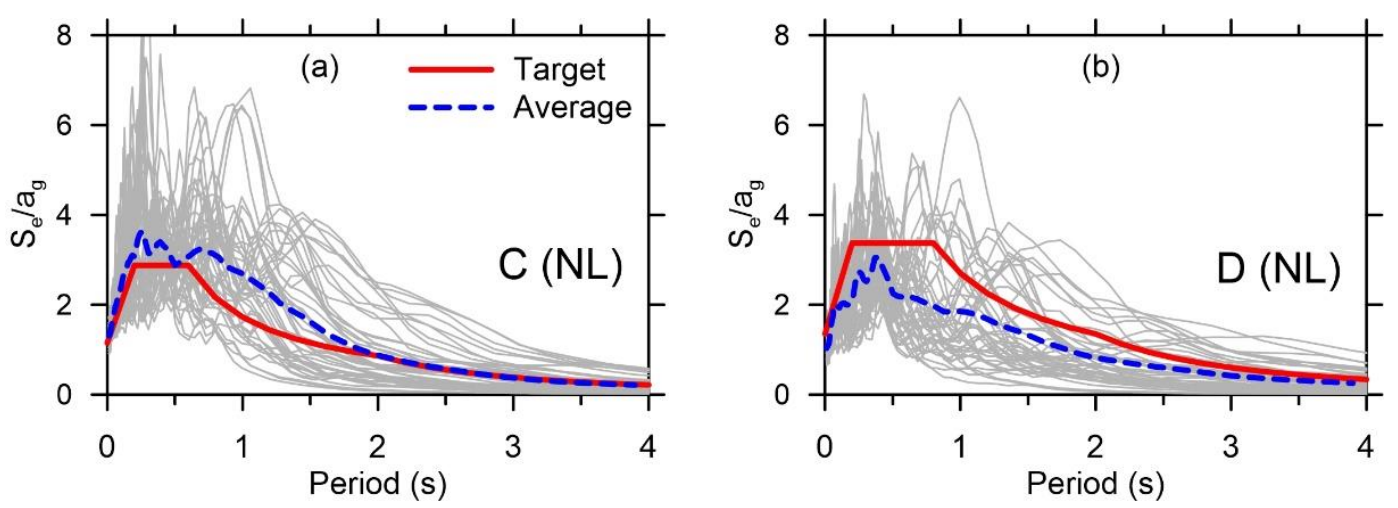

Figure 7. Spectral shapes from the nonlinear (NL) analyses with the design spectrum: (a) site classes C; (b) site classes D.
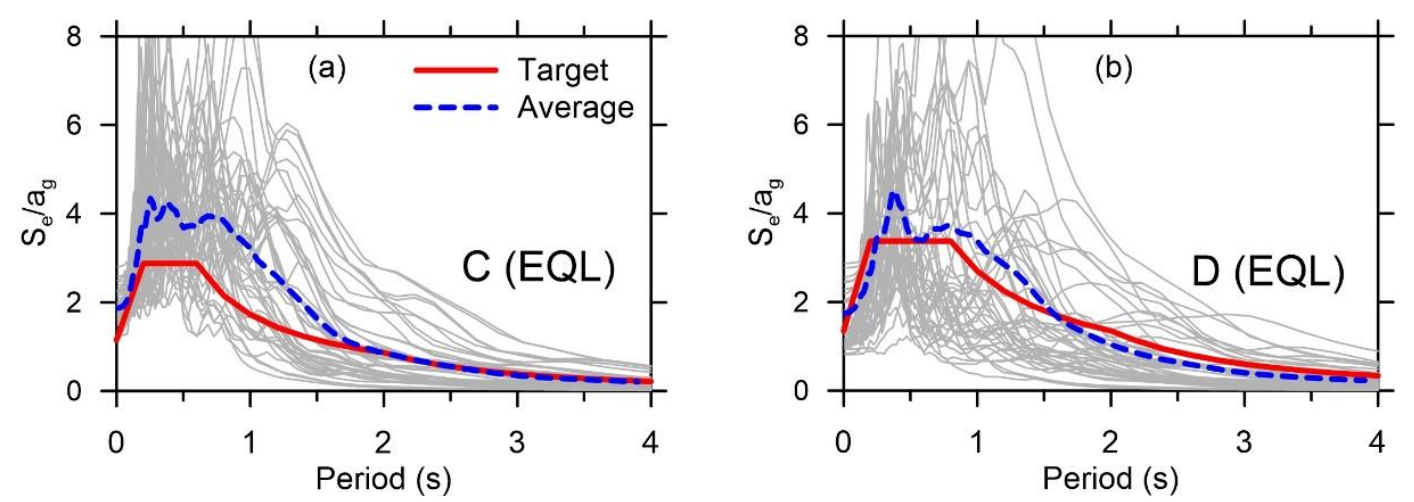

Figure 8. Spectral shapes from the equivalent linear (EQL) analyses with the design spectrum: (a) site classes C; (b) site classes D.

Figure 9 shows a comparison of the NL and EQL analysis response spectra and the design spectrum. As can be seen from the figure, the mean normalized response spectrum in the case of the EQL analysis is higher than that of the NL analysis in both the site classes, especially near the natural site periods. The NL analysis predicts smaller spectral accelerations from $0.2 \mathrm{~s}$ to $1.6 \mathrm{~s}$ in case of profiles of site class $\mathrm{C}$, whereas the period range extends up to $2.4 \mathrm{~s}$ in case of site class $\mathrm{D}$ profiles. This difference is attributed to the persistent softening of properties used in the nonlinear analysis which is not the case in the EQL analysis, where constant and strain compatible properties are used. These results are in line with the study of Rathje and Kottke [30].
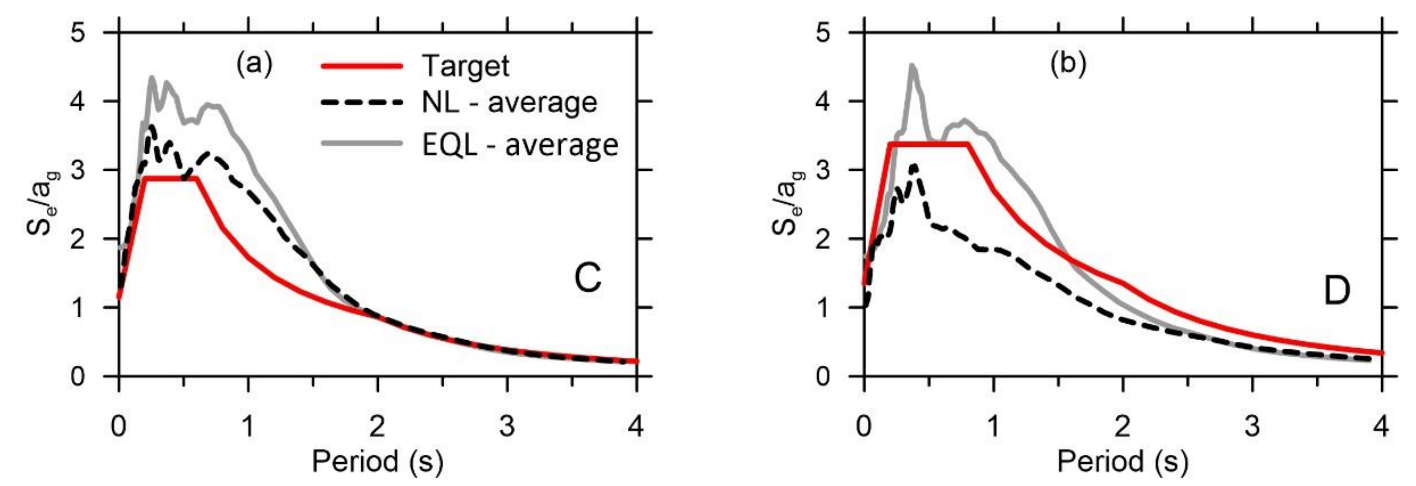

Figure 9. Spectral shape comparisons: (a) site classes C; (b) site classes D. 


\section{Maximum Shear Strain and PGA}

\subsection{Maximum Shear Strain}

Figure 10a-f show the maximum shear strain results obtained from the NL and EQL analysis for soil profiles. Overall, the NL and EQL results are closely matched. The difference between the EQL and NL increases as the higher strains are approached, which is in line with the study of Kim et al. [31]. The maximum shear strain of soil profiles calculated in this study is less than $0.5 \%$, excluding soil profile P6 (site class D) which reaches up to 1\% and 2.5\% for the NL and EQL approaches, respectively. In each soil profile, both the NL and EQL approaches share the same depth where the maximum shear strain is encountered, except soil profile P3. The difference in maximum shear strain depths between the two approaches in profile P3 can be attributed to the presence of a significant reversal of shear wave velocity in between $31 \mathrm{~m}$ to $40 \mathrm{~m}$.

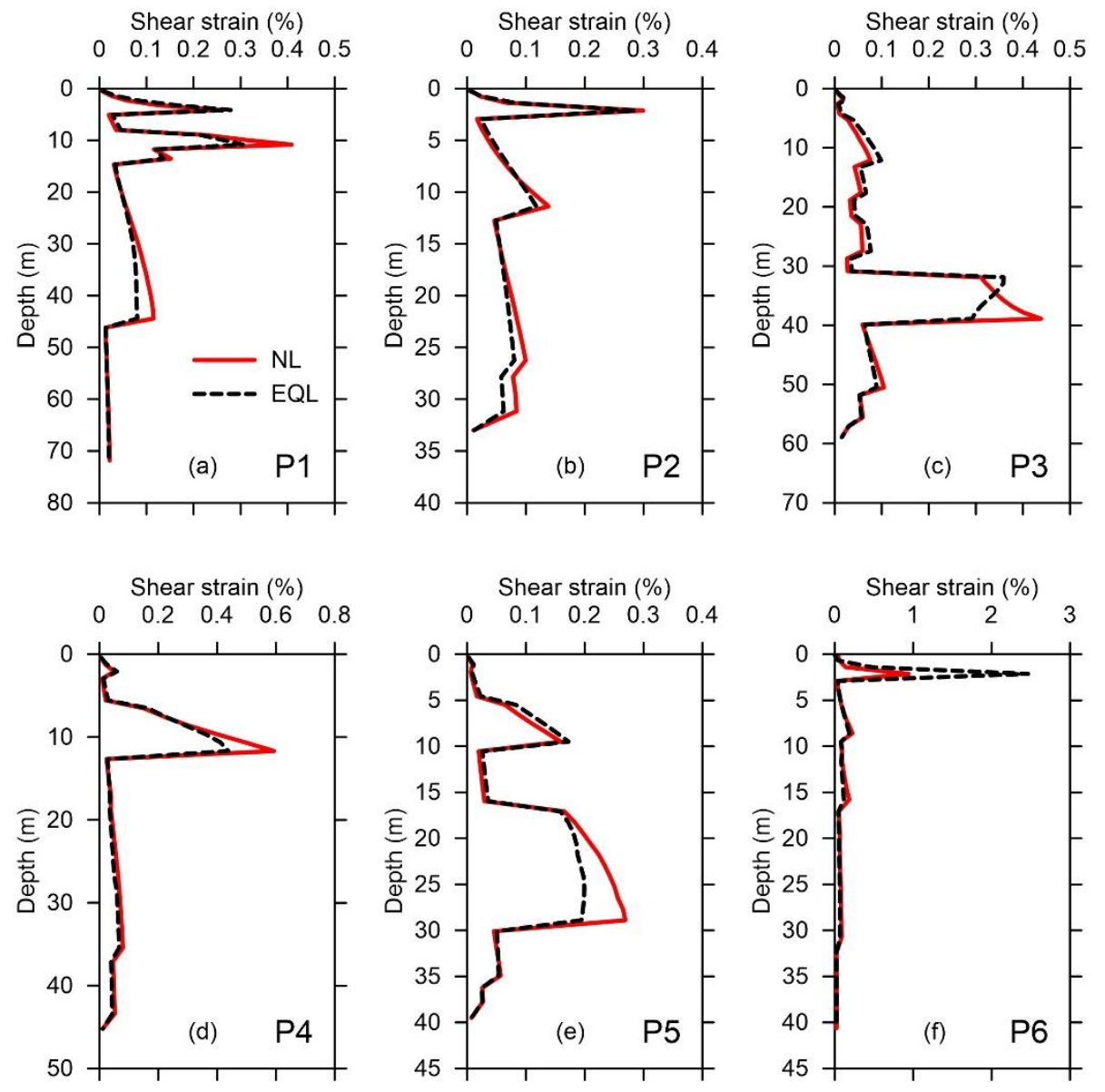

Figure 10. Maximum shear strain of soil profiles: (a-f) P1-P6.

\subsection{Maximum PGA}

Figure 11a-f show the NL and EQL maximum PGA for soil profiles. The difference in maximum PGA of NL and EQL at the surface is significant. The difference can be reached by $60 \%$, i.e., in the case of soil profile P6 which can be attributed to the softness of the profile leading to an increase in the shear strains, inducing more nonlinearity and resulting in the PGA difference at the surface. In the case of the NL approach, a certain amount of deamplification at the surface is observed in the case of soil profile P3 and soil profile P5. This can be attributed to the shear wave reversals present throughout the mentioned soil profiles. However, in the case of the EQL approach, the amount of deamplification is negligible as the surface is approached. This can be demonstrated by the fact that shear wave reversals 
result in the increased nonlinearity and a certain amount of deamplification occurs while performing the NL approach which is not the case in the EQL approach.
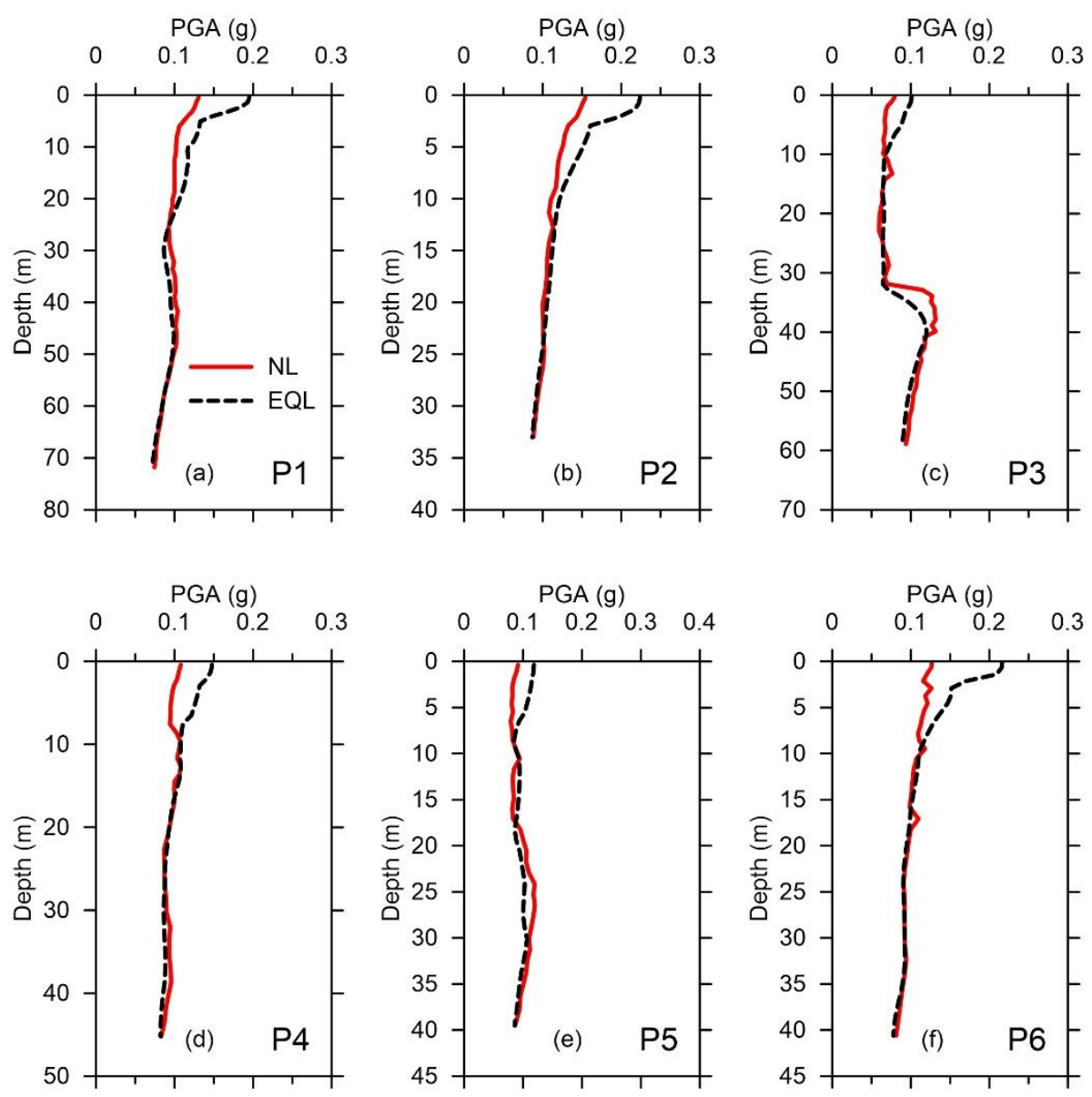

Figure 11. Maximum PGA of soil profiles: (a-f) P1-P6.

\section{Conclusions}

This study investigates the applicability of the Vietnamese seismic design code TCVN 9386:2012 using one-dimensional equivalent linear (EQL) and nonlinear (NL) site response approaches and discusses the relative differences between the two methods. A total of six soil profiles from three districts in Hanoi (Vietnam) and fifteen ground motions compatible with the rock design spectrum of the Vietnam design code were used as input data to conduct 1-D site response analyses. The following conclusions are achieved based on numerical analyses.

(1) The TCVN 9386:2012 underestimates the response amplification for soil profiles falling to site class $C$ in the range of period from 0.6 to $2 \mathrm{~s}$ and it overestimates the response across the whole period range for site class D (except in the case of the EQL method). It is therefore suggested that the seismic design code of Vietnam needs to be modified for both stiff profiles (i.e., site class $\mathrm{C}$ ) and soft profiles (i.e., site class D).

(2) It is well-known that the NL approach is appropriate to capture the actual response rather than the EQL approach, which is recommended to be used only in the case of shear strain level of less than $0.4 \%$ [31,32]. In this study, the spectra shapes from the NL analyses are higher than those of the EQL analyses, especially in soft soil (i.e., site class D). Overall, the shear strain and PGA obtained from the EQL method can adequately approximate the NL below the threshold shear strain levels. The difference between the NL and EQL results are greater for soft soil. For the PGA, the difference occurs at the ground surface, the PGA of the EQL analysis is higher than that of the NL. Based on the 
results of the NL analyses, the maximum shear strain is less than $0.5 \%$, except soil profile P6 with $1 \%$, and PGA is lower than $0.16 \mathrm{~g}$.

(3) The NL results revealed the occurrence of deamplification in the soft soils of Hanoi. It is recommended that the site-specific response analysis should be considered to perform the seismic design and response of above structures in site class D.

Author Contributions: Conceptualization and methodology, M.A. and D.P.; formal analysis, resources, and writing - original draft, V.-Q.N.; review and editing, D.-D.N. and N.-V.L. All authors have read and agreed to the published version of the manuscript.

Funding: This research was funded by a National Research Foundation of Korea (NRF) grant funded by the Korean government (MEST), grant number NRF-2019R1A2C1011323.

Acknowledgments: The authors would like to express their thanks to all participants.

Conflicts of Interest: The authors declare no conflicts of interest.

\section{References}

1. Kramer, S.L. Geotechnical Earthquake Engineering; Prentice-Hall: Upper Saddle River, NJ, USA, 1996.

2. Tapponnier, P.; Lacassin, R.; Leloup, P.H.; Schärer, U.; Dalai, Z.; Haiwei, W.; Xiaohan, L.; Shaocheng, J.; Lianshang, Z.; Jiayou, Z. The Ailao Shan/Red River metamorphic belt: tertiary left-lateral shear between Indochina and South China. Nature 1990, 343, 431. [CrossRef]

3. Lin, T.-L.; Wu, Y.-M.; Huang, B.-S.; Chang, C.-H.; Huang, W.-G.; Le, T.S.; Nguyen, Q.C. The first peak ground motion attenuation relationships for North of Vietnam. J. Asian Earth Sci. 2012, 43, 241-253.

4. Ngo, T.; Nguyen, M.; Nguyen, D. A review of the current Vietnamese earthquake design code. Spec. Issue Electron. J. Struct. Eng. (EJSE) Earthq. Eng. Low Moderate Seism. Reg. Southeast Asia Aust. 2008, 8, 32-41.

5. Shylamoni, P.; Choudhury, D.; Ghosh, S.; Ghosh, A.; Basu, P.C. Seismic ground response analysis of KK-NPP site in the event of NCO earthquake using DEEPSOIL. In Proceedings of the Geo-Congress 2014: Geo-characterization and Modeling for Sustainability, Atlanta, GA, USA, 23-26 February 2014; pp. 840-849.

6. Grasso, S.; Maugeri, M. The seismic microzonation of the city of Catania (Italy) for the maximum expected scenario earthquake of January 11, 1693. Soil Dyn. Earthq. Eng. 2009, 29, 953-962. [CrossRef]

7. Naik, N.; Choudhury, D. site specific ground response analysis for typical sites in Panjim city, Goa. In Proceedings of the Indian Geotechnical Conference, Roorkee, India, 22-24 December 2013.

8. Aaqib, M.; Sadiq, S.; Park, D.; Hashash, Y.M.; Pehlivan, M. Importance of implied strength correction for 1D site response at shallow sites at a moderate to low seismicity region. In Proceedings of the Geotechnical Earthquake Engineering and Soil Dynamics V, Austin, TX, USA, 10-13 June 2018; pp. 445-453.

9. Mahmood, K.; Farooq, K.; Memon, S.A. One dimensional equivalent linear ground response analysis-A case study of collapsed Margalla Tower in Islamabad during 2005 Muzaffarabad Earthquake. J. Appl. Geophys. 2016, 130, 110-117. [CrossRef]

10. Nhung, B.T.; Phuong, N.H.; Nam, N.T. Assessment of earthquake-induced liquefaction hazard in urban areas of Hanoi city using LPI-based method. Vietnam J. Earth Sci. 2018, 40, 78-96. [CrossRef]

11. Alexandr, G.; Chi, T.N. Liquefaction possibility of soil layers during earthquake in Hanoi. Int. J. GEOMATE 2017, 13, 148-155. [CrossRef]

12. Alexandr, G.; Chi, T.N. The impact of earthquakes on the tunnel from hanoi metro system when the tunnel has a horseshoe shape cross-section. Int. J. Civ. Eng. Technol. 2019, 10, 79-86.

13. Wen, K.-L.; Lin, C.-M.; Kuo, C.-H.; Phuong, N.H.; Hung, N.T.; Son, L.T. Site response analysis from microtremor survey in the Hanoi, Vietnam. In Proceedings of the Geophysics-Cooperation and Sustainable Development, Hanoi, Vietnam, 30 September 2012.

14. TCVN9386:2012. TCVN 9386:2012-Design of Structures for Earthquake Resistances; Construction Publishing House: Hanoi, Vietnam, 2012. (In Vietnamese)

15. Code, P. Eurocode 8: Design of structures for earthquake resistance-part 1: General rules, seismic actions and rules for buildings. In Brussels European Commission Standard; CEN: Brussels, Belgium, 2005.

16. Xuyen, N.D. Research and Forecasting Earthquakes and Ground Movements in Vietnam; Vietnam Institute of Geophysics: Hanoi, Vietnam, 2005. (In Vietnamese) 
17. Hashash, Y.; Musgrove, M.; Harmon, J.; Ilhan, O.; Groholski, D.; Phillips, C.; Park, D. DEEPSOIL 7.0, User Manual; University of Illinois at Urbana-Champaign: Springfield, IL, USA, 2017.

18. Matasović, N.; Vucetic, M. Cyclic characterization of liquefiable sands. J. Geotech. Eng.-ASCE 1993, 119, 1805-1822. [CrossRef]

19. Darendeli, M.B. Development of a New Family of Normalized Modulus Reduction and Material Damping Curves. Ph.D. Thesis, University of Texas at Austin, Austin, TX, USA, 2001.

20. Sadiq, S.; Nguyen, V.Q.; Jung, H.; Park, D. Effect of Flexibility Ratio on Seismic Response of Cut-and-Cover Box Tunnel. Adv. Civ. Eng. Mater. 2019, 2019. [CrossRef]

21. Hashash, Y.M.; Dashti, S.; Musgrove, M.; Gillis, K.; Walker, M.; Ellison, K.; Basarah, Y.I. Influence of Tall Buildings on Seismic Response of Shallow Underground Structures. J. Geotech. Geoenviron. Eng. 2018, 144, 04018097. [CrossRef]

22. Ding, Y.; Wang, G.; Yang, F. Parametric investigation on the effect of near-surface soil properties on the topographic amplification of ground motions. Eng Geol. 2020, 273, 105687. [CrossRef]

23. Harmon, J.; Hashash, Y.M.; Stewart, J.P.; Rathje, E.M.; Campbell, K.W.; Silva, W.J.; Xu, B.; Musgrove, M.; Ilhan, O. Site Amplification Functions for Central and Eastern North America-Part I: Simulation Data Set Development. Earthq. Spectra 2019, 35, 787-814. [CrossRef]

24. Nguyen, D.-D.; Park, D.; Shamsher, S.; Nguyen, V.-Q.; Lee, T.-H. Seismic vulnerability assessment of rectangular cut-and-cover subway tunnels. Tunn. Undergr. Space Technol. 2019, 86, 247-261. [CrossRef]

25. Nguyen, D.-D.; Lee, T.-H.; Nguyen, V.-Q.; Park, D. Seismic damage analysis of box metro tunnels accounting for aspect ratio and shear failure. Appl. Sci. 2019, 9, 3207. [CrossRef]

26. Jacky, J. Pressure in soils. In Proceedings of the 2nd International Conference of Soil Mechanic and Foundation Engineering, Rotterdam, The Netherlands, 21-30 June 1948.

27. Marto, A.; Tan, C.S.; Leong, T.K. Universal correlation of shear wave velocity and standard penetration resistance. Electron. J. Geotech. Eng. 2013, 18, 2727-2738.

28. Trung, G.K.; Vinh, N.D.; Men, D.T. Soil Classification and Seismic Site Response Analysis for Some Areas in Hanoi City. VNU J. Sci. Earth Envr. Sci. 2018, 34. [CrossRef]

29. Moghadam, M.R.; Baziar, M.H. Seismic ground motion amplification pattern induced by a subway tunnel: Shaking table testing and numerical simulation. Soil Dyn. Earthq. Eng. 2016, 83, 81-97. [CrossRef]

30. Rathje, E.; Kottke, A. Relative differences between equivalent linear and nonlinear site response methods. In Proceedings of the 5th International Conference on Earthquake Geotechnical Engineering, Santiago, Chile, 10-13 January 2011; pp. 10-13.

31. Kim, B.; Hashash, Y.M.; Stewart, J.P.; Rathje, E.M.; Harmon, J.A.; Musgrove, M.I.; Campbell, K.W.; Silva, W.J. Relative differences between nonlinear and equivalent-linear 1-D site response analyses. Earthq. Spectra 2016, 32, 1845-1865. [CrossRef]

32. Kaklamanos, J.; Baise, L.G.; Thompson, E.M.; Dorfmann, L. Comparison of 1D linear, equivalent-linear, and nonlinear site response models at six KiK-net validation sites. Soil Dyn. Earthq. Eng. 2015, 69, 207-219. [CrossRef]

(C) 2020 by the authors. Licensee MDPI, Basel, Switzerland. This article is an open access article distributed under the terms and conditions of the Creative Commons Attribution (CC BY) license (http://creativecommons.org/licenses/by/4.0/). 